\title{
Complications of Injectable Soft Tissue Filler
}

\author{
Woo Young Choi ${ }^{1}$, \\ Hyun Woo Cho ${ }^{2}$, Dong Won Lee ${ }^{1}$ \\ ${ }^{1}$ Department of Plastic and \\ Reconstructive Surgery, Yonsei University \\ Health System, Severance Hospital, Seoul; \\ ${ }^{2}$ Eight Private Cosmetic Clinic, Seoul, \\ Korea
}

No potential conflict of interest relevant to this article was reported.

\begin{abstract}
Background Soft tissue fillers have been used widely in recent years. As the use of filler increases, many complications have arisen. The complications should be prevented and if it occurs effective treatments are necessary to achieve a satisfying aesthetic result. In this article, we discuss the commonly used soft tissue filler and their complications. Methods We divided the soft tissue filler into three groups according to its origin. The possible complications and management according to the kind of filler were reviewed. Results Soft tissue fillers can be divided into autologous, biologic, and synthetic groups. Local reaction in the injection site is a common and minimal complication. Misplacement, allergic reaction, infection, and delayed granulomatous reaction can occur. Skin necrosis and visual impairment can occur. It is desirable to have proficiency of basic injection techniques such as aspiration before injection, injection with needle withdrawal, slow injection of small amount, using the blunt-tipped microcannula, pinching and tenting. Conclusions Soft tissue filler is a simple and safe material to soft tissue augmentation. Clinicians should know about the property and complications of the commonly used fillers. Also clinicians should be well aware of preventing and treating the complications.
\end{abstract}

Keywords Hyaluronic acid, Biofilms, Vision disorders, Necrosis

\section{INTRODUCTION}

Soft tissue fillers for soft tissue augmentation and the correction of wrinkles have been used widely in recent years. Various kinds of products have been developing and the demand for these products is growing more and more rapidly. The popularity of soft tissue fillers was based on the safety profile, easy application and low complications rate [1]. As the use of fillers increases, many complications have arisen recently. The range of complications varies widely. Local and temporary reaction to the filler is common and self-limited. Ozturk et al. [1] named the minimal and self-limited complication simply as adverse sequelae. Misplacement of filler, allergic reaction, infection and biofilm formation, and delayed granulomatous reaction can occur and proper treatments are necessary [1-3]. Skin ne-

Received: Feb 4, 2015 Revised: Feb 9, 2015 Accepted: Feb 10, 2015 Correspondence: Dong Won Lee Department of Plastic and Reconstructive Surgery, Yonsei University College of Medicine, 50 Yonsei-ro,

Seodaemun-gu, Seoul 120-752, Korea. E-mail: xyphoss@yuhs.ac

Copyright $\odot 2015$ The Korean Society for Aesthetic Plastic Surgery.

This is an Open Access article distributed under the terms of the Creative Commons Attribution Non-Commercial License (http://creativecommons.org/licenses/by-nc/3.0/) which permits unrestricted non-commercial use, distribution, and reproduction in any medium, provided the original work is properly cited. www.e-aaps.org crosis and visual impairment are not common but it is a disaster to both the patient and the clinician $[4,5]$. These complications have to be treated immediately and properly. Clinicians are familiar with the nature and property of most commonly used fillers and their procedure technique. Enough practice is necessary to prevent various complications because injection technique is critical. Although clinicians take care of above-mentioned factors, complications can develop unexpectedly. Clinicians should be aware of the method to deal with the complications. In this article, we introduce the three different groups of fillers according to their origin and discuss properties of each filler and possible complications. We also review how to avoid or manage the complications of soft tissue fillers.

\section{Classification of fillers}

Recently, various kind of soft tissue filler are available. Each filler has its own property. So the clinician has to choose proper the filler according to the patient's need to obtain good aesthetic result and to prevent undesired complications. In order to understand the nature of each filler, filler can be categorized the three broad groups, autologous, biologic, and synthetic filler, according to origin [6]. First, autologous filler can be obtained from own tissue such as dermis, fascia, cartilage, and fat [6-8]. Among them, autologous fat is most common injectable material. Autologous fat is regarded as ideal 
material in terms of nontoxicity, noncarcinogenicity, and biocompatibility. But a major drawback is its unpredictable absorption rate. And donor site morbidity is inevitable to obtain the fat [8]. So autologous fat graft is a good but somewhat inconvenient option compared with commercial products. Second is biologic filler. This is made up of biologic materials which are organic source from human, animal, or bacteria [6]. Biologic fillers have been used widely. However they can cause hypersensitivity reaction and immune rejection response and the effect lasts temporarily [9]. The commonly used biologic fillers are acellular soft-tissue matrix, collagen, and hyaluronic acid (HA) $[9,10]$. Collagen fillers are derived from materials extracted from bovine, porcine, and human body. CosmoDerm $^{\circledR}$ and CosmoPlast ${ }^{\circledR}$ containing the type 1 collagen derived from bioengineered skin [11]. This filler was created based on the idea that as type 1 collagen decreases with age, dermis loses its elasticity [11]. It can be used with HA fillers together. The benefit is decreased downtime, decreased bruising, decreased pain on injection [11]. HA filler is the most commonly used one. HA is a glycosaminoglycan which is a component of connective tissue such as bone, cartilage, skin, and synovial fluid. The typical product of HA filler is Restylane $^{\circledR}[12,13]$. Restylane ${ }^{\circledR}$ is a nonanimal stabilized HA gel and was approved by Food and Drug Administration (FDA) in 2003 for facial wrinkle correction [6]. It is made from bacteria by biofermentaion process and has less hypersensitivity reactions and transmission of harmful infectious source [14]. Restylane ${ }^{\circledR}$ subdivides into Restylane Touch (Fine Lines), Restylane, Perlane according to difference size of the constituent particle [13]. Third, there is the synthetic filler which is made using silicone, polymethylmethacrylate (PMMA), Calcium hydroxyapatite, and Poly-L-lactic acid (PLLA) [6]. The effect of synthetic filler continues permanently. Silicone had been used for aesthetic purpose in the past, but it has many problems. It becomes hardness and migrates. Also silicone causes inflammation and skin necrosis. ArteFill ${ }^{\circledR}$ is made from PMMA microspheres suspended in bovine collagen. After injection of ArteFill ${ }^{\oplus}$, bovine collagen is absorbed. PMMA is surrounded by patient's own collagen and becomes stable. By this principle, it makes that ArteFill ${ }^{\circledR}$ continues permanently [15]. Radiesse ${ }^{\circledR}$ is made from a mixture of calcium hydroxyapatite and polysaccharide gel in the ratio of three to seven [16]. Sculptra ${ }^{\circledR}$ is made from the PLLA. The advantage of Sculptra ${ }^{\circledR}$ is excellent biocompatibility $[17,18]$. The permanent filler remains in the body for a long time, it is more difficult to manage the complication than reversible filler.

\section{The complication of soft tissue filler}

\section{The local reaction in the filler injection site}

Bruise, swelling, redness, tenderness, and pain in the filler injection site are the most commonly appearing complications. Narins et al. [14] revealed that over $90 \%$ of patients treated with HA filler (Restylane $^{\circledR}$ ) or bovine collagen (Zyplast ${ }^{\circledR}$ ) showed theses symptoms and which improved within 7 days or less in his multicenter com- parative study. Although this local reaction is minor and self-limited, clinicians have to notify patients of the possibility of local reaction. Especially, the patient who takes anticoagulant drugs requires careful attention. The patient who takes aspirin due to cardiac disease or cerebral infarction has to stop the drugs five or seven days before the procedure. Nonsteroidal anti-inflammatory drug (NSAID), vitamin E, and herbal medicine also have to be stopped seven or ten days before the procedure because these dietary supplements can alter the coagulation $[3,19]$. So although filler injection is a simple technique, checking the general condition of patient and the selection of proper patient are important. Also the explanation of minimal complications to patient is important. So if we reduce the local reaction, patient satisfaction would be improved.

\section{Filler placement}

Depth of injection determines the filler placement [2]. Filler injection too superficial or too deep can cause the problems. Generally, if fillers are injected into too superficially, surface of injected site could be irregular and lumpy. It could become hard and palpable on the skin. Therefore fillers should be injected into the appropriate layer according to each kind of filler.

\section{HA filler}

HA filler should be injected into the deep dermal layer or subdermal layer [20]. If HA filler is injected too superficially, it would be appear as a visible lump [21]. The color of skin could be bluish in the around the injection area. This appearance is known as Tyndall effect. Tyndall effect is that different wavelength light is scattered differently on the particles it encounters [20,22]. That is, bluer and shorter wavelength light is scattered much more than redder and longer wavelength light [22]. So too superficial injection of HA filler looks bluish and inversely it warns that HA filer was injected into a too superficial layer [22]. Massaging the injection site can relieve the hardness and lump [22,23]. Hyaluronidase can also be helpful. There is no clear standard how to use hyaluronidase. The activity of hyaluronidase depends on the kind of $\mathrm{HA}$ filler, $\mathrm{pH}$, and biologic factor of patient. Bailey et al. [20] used 75 unit hyaluronidase mixed with $1 \%$ lidocaine $1.5 \mathrm{~mL}$. Brody [23] reported that 15 unit hyaluronidase could relieve the problems within 24-48 hours. DeLorenzi [2] reported effective treatment using 15-50 unit hyaluronidase. Skin test is needed prior to using hyaluronidase and local wheal and flare reaction is positive reaction within 5 minutes after the injection of 3 units $(0.02 \mathrm{~mL})$ intradermally [23].

\section{Calcium hydroxylapatite}

Calcium hydroxylapatite should be injected into the deep dermal layer and subdermal layer [20]. If calcium hydroxylapatite is injected into the too superficial layer, it would appear as a white nodular finding. And normal muscle movement results in filler migration and dislocation especially in the lip. Eventually, this action causes 
nodule formation superficially [24]. Therefore Radiesse ${ }^{\circledR}$ which is a mixture of calcium hydroxyapatite with polysaccharide is not recommended for injection to the lip [3]. When nodular formation occurs after injection of calcium hydroxyapatite, intralesional steroid injection, massage, and direct excision can be treatment [24].

\section{PMMA}

PMMA is one kind of synthetic filler and permanent filler. It is available in the United States market as Artefill ${ }^{\circledR}$ and in the Europe as Artecoll $^{\circledR}[20]$. This filler also should be injected to the deep dermal layer and subdermal layer [20]. PMMA can cause long lasting pruritus and redness. It is not common, but hypertrophic scar can be developed $[20,25]$. Pruritus and redness in local area can be relieved through intralesional steroid injection and application of steroid ointment on the wound. Intralesional steroid injection and pulsed dye laser can be effective to the hypertrophic scar $[3,25]$.

\section{Infection}

The face has good blood supply and metabolic rate, so infection after filler injection is not common [26]. But basic antiseptic preparation using chlorhexidine and alcohol for face is important [3]. The reason why aseptic preparation and procedure is important is that bacterial infection can make biofilm. Once biofilm was made, bacteria have a safe room and bacteria grow very slowly, bacterial culture test shows usually negative [2]. Foreign body and implants contaminated by biofilm can cause chronic infection and repeated recurrence because it is difficult for the antibiotics to reach the bacteria $[2,27]$. Chronicity and recurrence of infection is critical consequence of bilfilm [26]. Complete resolution is impossible without removal of foreign body or implants with its biofilm [26]. This is also related to the delayed-out nodules formation. The common viral infection source is herpes simplex virus [2]. So some patients who have a history of herpes simplex infection may be given prophylactic antiviral drugs [2]. The patients infected with herpes simplex now should not be performed the filler injection [21]. In immunocompromised patients, candida infection can occur after filler injection [2]. So clinicians have to consider the general condition of patients as well as their needs.

\section{Allergic reaction}

All fillers except autologous tissue can cause foreign body reactions ranging from simple immune reaction to life-threatening anaphylaxis [20]. Skin test is a requisite procedure to prevent hypersensitivity reaction. The local allergic reaction such as erythema, induration, burning, and subcutaneous lumps can occur but does not develop long-lasting morbidity [20]. It can be relieved by using topical tacrolimus, antihistamine, intralesional steroid injection, and systemic steroid therapy [20]. Hypersensitivity reaction of HA filler is not common but sometimes is reported. Angioderma-type hypersensitivity of HA filler infection in the upper lip was reported [28].
The injection of lidocaine for nerve block or botulinum neurotoxin type A at the same session can result in hypersensitivity [3].

Hypersensitivity reaction cannot be predicted, thus clinicians should be well aware of the possibility of the hypersensitivity reactions from the fillers they used.

\section{Nodular reaction}

Nodules due to filler injection can be divided into two categories. First is the type developing just after injection. Nodules in this category are resulted from the above-mentioned too superficial injection. Another category is nodule developing a few months later. Generally, granulomatous reaction is mainly responsible for these delayed nodules. If the infection and inflammation may be developed after filler injection, delayed hypersensitivity reaction and sterile abscess can occur. This process can lead to granulomatous reaction and finally result in the inflammatory nodule or delayed nodule over time [29]. The main treatment of inflammatory nodule is reducing the inflammation. Local and systemic steroid therapy, intralesional steroid injection, antibiotics, hyaluronidase, 5-fluorouracil, allopurinol, surgical excision can be used [29].

Bovine collagen has high risk for hypersensitivity reaction. Heise et al. [30] reported that the patients who were negative in skin test showed temporary granulomatous inflammation from the delayed hypersensitivity reaction. And he recommended that bovine collagen injection should be performed at least four weeks after skin test [30]. In the case of HA fillers, most nodules are due to a too superficial injection because HA is absorbed and does not remain in the body for a long time. It is not common but delayed hypersensitivity reaction can result in granulomatous foreign body reaction and sterile abscess $[31,32]$. Macrophage and lymphocyte infiltration and foreign-body giant cell can be identified in the nodule by histologic stain. Management includes antibiotics, hyaluronidase, intralesional or systemic steroid therapy, and surgical excision [2,31]. PLLA is synthetic filler approved by the FDA as the filling material for the facial lipoatrophy in patient infected with human immunodeficiency virus (HIV) [33]. Delayed inflammatory nodule is most common in PLLA except the silicone. Valantin et al. [33] reported that among fifty patients, twenty-two patients developed the delayed inflammatory nodule. Those were palpable but non-visible micronodules and developed from six months to sixty months after injection [33]. Surgical excision is preferable choice of management and other medical treatments are not effective [29]. Calcium hydroxyapatite is a synthetic filler and it has low immune response. Deep dermal and subdermal layer are the proper layers of injection. The injection around lip should be avoided to prevent nodular formation [31,34]. Delayed nodule due to calcium hydroxyapatite usually occurs in twelve weeks. It appears as a subcutaneous white or yellow nodule. Intralesional steroid injection, fractional $\mathrm{CO}_{2}$ laser, and surgical excision would be effective treatment $[29,35]$. PMMA is difficult to resolve the misplacement of filler because it is permanent filler. Deep der- 
mal and subdermal layer are the proper layers for injection [20]. If filler injected to superficial layer, massage in the injection site can be resolve and minimal movement of lip can be help to prevent the nodular formation [15]. PMMA can also cause the delayed granulomatous reaction and make late-onset nodule. Intralesional steroid is effective and surgical excision can be possible [15,36]. Polyacrylamide has high biocompatibility and foreign body reaction is not common. However it can act as a good bed for normal flora in the skin and mucosa. This phenomenon makes the biofilm and causes chronic inflammation [37,38]. Chronic inflammatory nodule can occur from a few days to a few months, it usually accompanies erythema and pain $[39,40]$. This infectious nodule with biofilm has been distinguished from other delayed nodule, because steroid therapy can worsen symptoms through the formation of biofilm. Therefore aseptic procedure is especially important for injection of polyacrylamide [41].

\section{Skin necrosis}

One of the serious complications is skin necrosis. It results when the injected filler flows into the vessel directly and compresses the vessel to impede the blood supply $[3,20]$. Various fillers can cause skin necrosis. HA filler to improve the glabellar wrinkles caused arterial embolization, and calcium hydroxylapatite filler to augmentation of nose caused ocular ischemia and paralysis, and Juvederm Ultra Plus ${ }^{\circledR}$ for augmentation rhinoplasty caused oculomotor nerve palsy, and skin necrosis in the nose, glabella, and forehead $[5,42,43]$. The glabellar area is risk area because it has blood supply by the terminal branch of nasal dorsal artery [20]. Ozturk et al. [1] reported that skin necrosis occurred most frequently when filler was injected to the nose. If the filler flows into the vessel, pain immediately occurs. Subsequently blanching, duskiness, and ecchymosis follow. Pain, skin discoloration, swelling, bruise, and erythema continue in one or two days. Soft tissue defect, ulceration, and eschar occur in three or seven days. Ozturk et al. [1] reported that skin necrosis in direct filler injection site was $46.2 \%$ and skin necrosis in the area which has blood supply from impaired vessel was $28.2 \%$. When presymptom for skin necrosis occur after filler injection, immediate treatment should start for increasing the circulation. Covering warm gauze, tapping the area, applying nitroglycerin, and prostaglandin administration could be performed $[3,20]$. Also local or systemic antibiotics, local or systemic steroid, low-molecular-weight heparin, and local hyperbaric treatment could be effective $[1,20]$. Once skin necrosis has occurred, intensive wound care and meticulous surgical debridement of necrotic tissue is required [1,5]. Preventing secondary infection and accelerating reepithelization are also required [1]. Epidermal growth factor and sodium hyaluronate gel can be tried [5]. In another report, two patients who developed the nasal skin necrosis after HA filler injection were treated successfully with autologous adipose derive stem cell [44]. It is not clear the effect of hyaluronidase for skin necrosis due to HA filler. Kim et al. [45] per- formed the animal experiment to evaluate the role of hyaluronidase. They injected hyaluronidase subcutaneously to the ear which had auricular arteries injury by HA filler. The subcutaneous injection of hyaluronidase within 4 hours could minimize the skin necrosis [45].

\section{Visual impairment}

Visual impairment is the worst complication after filler injection. It develops because the filler flows reversely from the peripheral vessel to ophthalmic artery. And this occurs the ophthalmic artery embolism $[42,46,47]$. This complication can be developed from any kind of filler such as HA, PMMA, collagen, injectable dermal matrix, and PLLA. Glabellar area is most risk area, and nose and forehead are also at risk. So clinicians have to pay attention to injections in this area. Visual impairment occurs within the few minutes after injection. It always develops with pain in the involved eye. Other symptoms are sweating, nausea, vomiting, headache, paralysis of oculomotor muscle and ptosis [42]. There are subjective symptoms such as headache, toothache, and pain in the involved eye. Clinicians should keep in mind of these symptoms during procedure [42,47]. If patient complains these complications, the filler injection has to stop immediately [47]. The procedure for vasodilatation, gently massage and application of warm gauze and nitroglycerine paste, is necessary [48]. Serious visual impairment and skin necrosis are adverse effect on both the patient and the clinician. So clinicians need the sufficient education on filler and technical practice.

There are common precautions and tips for prevent the serious complication such as skin necrosis and visual impairment. Basic techniques are aspiration before injection, injection with needle withdrawal, slow injection of small amount, using the blunt-tipped microcannula, and pinching and tenting of skin $[1,4,20,48,49]$. In the glabellar area, the needle tip should be placed the superficially and medially to avoid the injury of supratrochlear vessels $[20,48]$.

\section{CONCLUSION}

Soft tissue fillers have been used widely in these days and the demand for filler is expected to increase more and more. Various kinds of filler are developed and commercialized. Soft tissue filler is a simple and easy method to achieving the satisfying aesthetic result compared with other methods. But indiscreet use of filler can cause many complications. To reduce the complications, clinicians should know the properties and possible complications of the commonly used fillers. Sufficient education and practice of injection techniques is important.

\section{REFERENCES}

1. Ozturk CN, Li Y, Tung R, et al. Complications following injection of soft-tissue fillers. Aesthet Surg J 2013;33:862-77.

2. DeLorenzi C. Complications of injectable fillers, part I. Aesthet Surg J 
2013;33:561-75.

3. Cohen JL. Understanding, avoiding, and managing dermal filler complications. Dermatol Surg 2008;34 Suppl 1:S92-9.

4. Lazzeri D, Agostini T, Figus M, et al. Blindness following cosmetic injections of the face. Plast Reconstr Surg 2012;129:995-1012.

5. Kwon SG, Hong JW, Roh TS, et al. Ischemic oculomotor nerve palsy and skin necrosis caused by vascular embolization after hyaluronic acid filler injection: a case report. Ann Plast Surg 2013;71:333-4.

6. Warren RJ, Neligan PC. Plastic surgery: aesthetic surgery. 3rd ed. St. Louis, MO: Elsevier Health Sciences; 2012.

7. Fagien S. Facial soft-tissue augmentation with injectable autologous and allogeneic human tissue collagen matrix (autologen and dermalogen). Plast Reconstr Surg 2000;105:362-73; discussion 74-5.

8. Chajchir A. Fat injection: long-term follow-Up. Aesthetic Plast Surg 1996;20:291-6.

9. Friedman PM, Mafong EA, Kauvar AN, et al. Safety data of injectable nonanimal stabilized hyaluronic acid gel for soft tissue augmentation. Dermatol Surg 2002;28:491-4.

10. Cheng JT, Perkins SW, Hamilton MM. Collagen and injectable fillers. Otolaryngol Clin North Am 2002;35:73-85, vi.

11. Bauman L. CosmoDerm/CosmoPlast (human bioengineered collagen) for the aging face. Facial Plast Surg 2004;20:125-8.

12. Monheit GD, Prather CL. Juvéderm: a hyaluronic acid dermal filler. J Drugs Dermatol 2007;6:1091-5.

13. Rohrich RJ, Ghavami A, Crosby MA. The role of hyaluronic acid fillers (Restylane) in facial cosmetic surgery: review and technical considerations. Plast Reconstr Surg 2007;120:41s-54s.

14. Narins RS, Brandt F, Leyden J, et al. A randomized, double-blind, multicenter comparison of the efficacy and tolerability of Restylane versus Zyplast for the correction of nasolabial folds. Dermatol Surg 2003;29: 588-95.

15. Lemperle G, Gauthier-Hazan N, Lemperle M. PMMA-Microspheres (Artecoll) for long-lasting correction of wrinkles: refinements and statistical results. Aesthetic Plast Surg 1998;22:356-65.

16. Siclovan HR, Jomah JA. Injectable calcium hydroxylapatite for correction of nasal bridge deformities. Aesthetic Plast Surg 2009;33:544-8.

17. Sadove R. Injectable poly-L: -lactic acid: a novel sculpting agent for the treatment of dermal fat atrophy after severe acne. Aesthetic Plast Surg 2009;33:113-6.

18. Lacombe V. Sculptra: a stimulatory filler. Facial Plast Surg 2009;25:95-9.

19. Dinehart SM, Henry L. Dietary supplements: altered coagulation and effects on bruising. Dermatol Surg 2005;31:819-26; discussion 26.

20. Bailey SH, Cohen JL, Kenkel JM. Etiology, prevention, and treatment of dermal filler complications. Aesthet Surg J 2011;31:110-21.

21. Narins RS, Jewell M, Rubin M, et al. Clinical conference: management of rare events following dermal fillers--focal necrosis and angry red bumps. Dermatol Surg 2006;32:426-34.

22. Hirsch RJ, Narurkar V, Carruthers J. Management of injected hyaluronic acid induced Tyndall effects. Lasers Surg Med 2006;38:202-4.

23. Brody HJ. Use of hyaluronidase in the treatment of granulomatous hyaluronic acid reactions or unwanted hyaluronic acid misplacement. Dermatol Surg 2005;31:893-7.

24. Berlin A, Cohen JL, Goldberg DJ. Calcium hydroxylapatite for facial rejuvenation. Semin Cutan Med Surg 2006;25:132-7.

25. Lemperle G, Romano JJ, Busso M. Soft tissue augmentation with artecoll: 10-year history, indications, techniques, and complications. Dermatol Surg 2003;29:573-87.

26. Daines SM, Williams EF. Complications associated with injectable soft-tissue fillers: a 5-year retrospective review. JAMA Facial Plast Surg 2013;15:226-31.

27. Monheit GD, Rohrich RJ. The nature of long-term fillers and the risk of complications. Dermatol Surg 2009;35 Suppl 2:1598-604.

28. Leonhardt JM, Lawrence N, Narins RS. Angioedema acute hypersensitivity reaction to injectable hyaluronic acid. Dermatol Surg 2005;31: 577-9.

29. Andre P, Lowe NJ, Parc A, et al. Adverse reactions to dermal fillers: a review of European experiences. J Cosmet Laser Ther 2005;7:171-6.

30. Heise H, Zimmermann R, Heise P. Temporary granulomatous inflammation following collagen implantation. J Craniomaxillofac Surg 2001; 29:238-41.

31. Ledon JA, Savas JA, Yang S, et al. Inflammatory nodules following soft tissue filler use: a review of causative agents, pathology and treatment options. Am J Clin Dermatol 2013;14:401-11.

32. Bardazzi F, Ruffato A, Antonucci A, et al. Cutaneous granulomatous reaction to injectable hyaluronic acid gel: another case. J Dermatolog Treat 2007;18:59-62.

33. Valantin MA, Aubron-Olivier C, Ghosn J, et al. Polylactic acid implants (New-Fill) to correct facial lipoatrophy in HIV-infected patients: results of the open-label study VEGA. AIDS 2003;17:2471-7.

34. Jansen DA, Graivier MH. Evaluation of a calcium hydroxylapatitebased implant (Radiesse) for facial soft-tissue augmentation. Plast Reconstr Surg 2006;118:22S-30S, discussion 1S-3S.

35. Reddy KK, Brauer JA, Anolik R, et al. Calcium hydroxylapatite nodule resolution after fractional carbon dioxide laser therapy. Arch Dermatol 2012;148:634-6.

36. Alcalay J, Alkalay R, Gat A, et al. Late-onset granulomatous reaction to Artecoll. Dermatol Surg 2003;29:859-62.

37. Christensen LH. Host tissue interaction, fate, and risks of degradable and nondegradable gel fillers. Dermatol Surg 2009;35 Suppl 2:1612-9.

38. Bello G, Jackson IT, Keskin M, et al. The use of polyacrylamide gel in soft-tissue augmentation: an experimental assessment. Plast Reconstr Surg 2007;119:1326-36.

39. Bjarnsholt T, Tolker-Nielsen T, Givskov M, et al. Detection of bacteria by fluorescence in situ hybridization in culture-negative soft tissue filler lesions. Dermatol Surg 2009;35 Suppl 2:1620-4.

40. Alijotas-Reig J, Garcia-Gimenez V, Miró-Mur F, et al. Delayed immunemediated adverse effects related to polyacrylamide dermal fillers: clinical findings, management, and follow-up. Dermatol Surg 2009;35 Suppl 1: 360-6.

41. Yagi Y, Kato K, Murakami D, et al. Use of Aquamid as a filler for facial 
rejuvenation in orientals. J Plast Reconstr Aesthet Surg 2009;62:1245-9.

42. Sung MS, Kim HG, Woo KI, et al. Ocular ischemia and ischemic oculomotor nerve palsy after vascular embolization of injectable calcium hydroxylapatite filler. Ophthal Plast Reconstr Surg 2010;26:289-91.

43. Schanz S, Schippert W, Ulmer A, et al. Arterial embolization caused by injection of hyaluronic acid (Restylane). Br J Dermatol 2002;146: 928-9.

44. Sung HM, Suh IS, Lee HB, et al. Case Reports of Adipose-derived Stem Cell Therapy for Nasal Skin Necrosis after Filler Injection. Arch Plast Surg 2012;39:51-4.

45. Kim DW, Yoon ES, Ji YH, et al. Vascular complications of hyaluronic acid fillers and the role of hyaluronidase in management. J Plast Reconstr Aesthet Surg 2011;64:1590-5.
46. Kubota T, Hirose H. Permanent loss of vision following cosmetic rhinoplastic surgery. Jpn J Ophthalmol 2005;49:535-6.

47. Kim YJ, Kim SS, Song WK, et al. Ocular ischemia with hypotony after injection of hyaluronic acid gel. Ophthal Plast Reconstr Surg 2011;27: e152-5.

48. Glaich AS, Cohen JL, Goldberg LH. Injection necrosis of the glabella: protocol for prevention and treatment after use of dermal fillers. Dermatol Surg 2006;32:276-81.

49. Hexsel D, Soirefmann M, Porto MD, et al. Double-blind, randomized, controlled clinical trial to compare safety and efficacy of a metallic cannula with that of a standard needle for soft tissue augmentation of the nasolabial folds. Dermatol Surg 2012;38:207-14. 